\title{
Commentary: Avoiding acute kidney injury after cardiac operations: Searching for the holy grail is not easy
}

\author{
Victor A. Ferraris, MD, PhD
}

\author{
From the Department of Surgery, University of Kentucky, Lexington, Ky. \\ Disclosures: Author has nothing to disclose with regard to commercial support \\ Received for publication Nov 25, 2018; accepted for publication Nov 26, 2018; available ahead of print Jan 9, \\ 2019 \\ Address for reprints: Victor A. Ferraris, MD, PhD, University of Kentucky, A301 Kentucky Clinic, 740 S Lime- \\ stone, Lexington, KY 40536-0284 (E-mail: ferraris@uky.edu). \\ J Thorac Cardiovasc Surg 2019;158:500-1 \\ $0022-5223 / \$ 36.00$ \\ Copyright (c) 2018 by The American Association for Thoracic Surgery \\ https://doi.org/10.1016/j.jtcvs.2018.11.078
}

Searching through the literature to identify potential causes and treatments of postoperative acute kidney injury (AKI) can be mind-boggling, frustrating, and more difficult than Indiana Jones searching for the holy grail. Predictors of postoperative AKI are abundant. Examples include, but are by no means limited to, serum biomarkers, ${ }^{1,2}$ urinary biomarkers, ${ }^{3,4}$ potentially modifiable clinical factors, ${ }^{5}$ and dynamic predictive scores that rely on the time of sampling before or after operation. ${ }^{6}$ A notably lacking source of predictors of AKI is an intraoperative marker that may predict early postoperative AKI. Many published reports of risk factors for AKI focus on postoperative variables, which may not provide actionable information to reduce AKI risk.

In Mukaida and colleagues' article $^{7}$ in this issue of the Journal, their exploration of AKI after cardiac operations provides intraoperative measures that may be early indicators of AKI. Perhaps more importantly, these early measures of AKI may trigger interventions for cardiac surgeons. who have been searching for the holy grail to reduce AKI associated with cardiopulmonary bypass for more than 40 years. ${ }^{8}$ They offer a possible predictive measure of AKI that can be obtained during cardiopulmonary bypass (CPB). There are at least 15 different literature reports that provide predictive algorithms for determining AKI after cardiac operations. ${ }^{9}$ These literature reports suggest that anywhere between 7 and 15 variables may be multivariate predictors of postoperative AKI. The predictive models for AKI requiring dialysis are the most robust, and most of these predictive models have external validation. Dialysis events after cardiac operations are rare $(1 \%-2 \%)$, however, and the delayed occurrence after operation limits the benefit of application of predictive scoring systems. A critical assessment of these prediction models suggests that models with a more sensitive definition of AKI suffer from differing definitions of AKI, small cohorts, lack of intraoperative variables, and the lack of external validation. $^{9}$ The take-home message from a literature tissues.

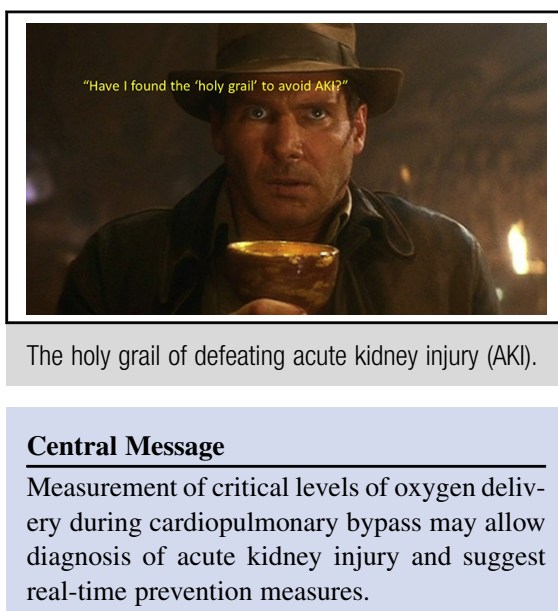

See Article page 492.

search about AKI and cardiac operations suggests that better prediction models for AKI not requiring dialysis are needed, especially because this form of AKI is much more common than postoperative dialysis-dependent AKI. An accurate model for prediction of postoperative AKI not requiring dialysis offers the possibility of avoiding a highly morbid and relatively common complication after cardiac operations. ${ }^{10,11}$

So, what is this intraoperative measure of AKI that may represent the holy grail of early detection and offers promise to reduce AKI after cardiac operations? Mukaida and colleagues ${ }^{7}$ used measurements of oxygen delivery $\left(\mathrm{Do}_{2}\right)$ during CPB to develop receiver operating characteristic curves and measures of the time that $\mathrm{Do}_{2}$ falls below a critical value to reflect relationships between $\mathrm{DO}_{2}$ and $\mathrm{AKI}$. In qualitative terms, Mukaida and colleagues ${ }^{7}$ found that the longer that $\mathrm{DO}_{2}$ levels during $\mathrm{CPB}$ were below a critical threshold, the more likely was the chance of AKI. Mukaida and colleagues ${ }^{7}$ developed receiver operating characteristic curves with 3 different critical thresholds for $\mathrm{Do}_{2}(300,280$, and $260 \mathrm{~mL} / \mathrm{min} / \mathrm{m}^{2}$ ). For those of you who (like me) do not remember what $\mathrm{Do}_{2}$ is, it is a composite measure of oxygen content (hematocrit dependent) times pump flow rate during $\mathrm{CPB}$. Lower values of $\mathrm{Do}_{2}$ imply less oxygen delivery to

There are several unique features of the analysis of Mukaida and colleagues ${ }^{7}$ that need to be pointed out. First, they performed all cardiopulmonary perfusions at normothermia. Oxygen dissociation curves depend on 
temperature, and therefore hemoglobin delivery in their study is likely to be different from oxygen delivery for the vast majority of patients who undergo hypothermia for CPB. Exactly how the results of Mukaida and colleagues ${ }^{7}$ translate to traditional hypothermic CPB is a little uncertain, but qualitative changes that they observed are likely to apply to patients undergoing hypothermic CPB. Second, for some reason Mukaida and colleagues ${ }^{7}$ chose to make perfusion time a dichotomous variable (above or below 121 minutes of perfusion time). I realize that the use of CPB time as a continuous variable would add complexity to the analysis; however, the qualitative findings they describe are likely to apply even in a more complex arrangement of the predictor variables. Perhaps, the most important feature of the analysis of Mukaida and colleagues ${ }^{7}$ is their creation of a predictor variable that indicates AKI risk (fraction of CPB time that $\mathrm{Do}_{2}$ levels were below critical values). Their key predictor variable is really a composite variable that appears to have value in AKI prediction. They call this variable time-dose response of $\mathrm{Do}_{2}$ during $\mathrm{CPB}$, and that is a mouthful to convey to readers. Nonetheless, it is possible (if not easy) to measure the time that $\mathrm{Do}_{2}$ falls below critical values. Many cardiopulmonary machines can provide nearly real-time measurements of flow times and hemoglobin oxygen content.

The holy grail of AKI prevention may well be related to minimizing the time that $\mathrm{Do}_{2}$ is less than specific critical values. The final common pathway for AKI reduction remains to be tested in clinical settings, especially in highrisk patients. Trials that test minimization of time that $\mathrm{DO}_{2}$ is less than critical values during $\mathrm{CPB}$ are necessary to support the contentions of Mukaida and colleagues.
This would involve carefully designed clinical trials that include real-time, nearly continuous, measurements of $\mathrm{Do}_{2}$ during $\mathrm{CPB}$. The really intriguing thing about these trial designs is that we may finally be nearing an intervention that can both measure and ultimately reduce AKI risk in cardiac surgical patients. I look forward to these results.

\section{References}

1. Haase M, Bellomo R, Devarajan P, Ma Q, Bennett MR, Möckel M, et al. Novel biomarkers early predict the severity of acute kidney injury after cardiac surgery in adults. Ann Thorac Surg. 2009;88:124-30.

2. Burra V, Nagaraja PS, Singh NG, Prabhakar V, Manjunatha N. Early prediction of acute kidney injury using serum phosphorus as a biomarker in pediatric cardiac surgical patients. Ann Card Anaesth. 2018;21:455-9.

3. Parikh CR, Mishra J, Thiessen-Philbrook H, Dursun B, Ma Q, Kelly C, et al. Urinary IL-18 is an early predictive biomarker of acute kidney injury after cardiac surgery. Kidney Int. 2006;70:199-203.

4. Metzger J, Mullen W, Husi H, Stalmach A, Herget-Rosenthal S, Groesdonk HV, et al. Acute kidney injury prediction in cardiac surgery patients by a urinary peptide pattern: a case-control validation study. Crit Care. 2016;20:157.

5. Karkouti K, Wijeysundera DN, Yau TM, Callum JL, Cheng DC, Crowther M, et al. Acute kidney injury after cardiac surgery: focus on modifiable risk factors. Circulation. 2009;119:495-502.

6. Haase-Fielitz A, Bellomo R, Devarajan P, Story D, Matalanis G, Dragun D, et al. Novel and conventional serum biomarkers predicting acute kidney injury in adult cardiac surgery-a prospective cohort study. Crit Care Med. 2009;37:553-60.

7. Mukaida H, Matsushita S, Kuwaki K, Inotani T, Minami Y, Saigusa A, et al Time-dose response of oxygen delivery during cardiopulmonary bypass predicts acute kidney injury. J Thorac Cardiovasc Surg. 2019;158:492-9.

8. Gailiunas P Jr, Chawla R, Lazarus JM, Cohn L, Sanders J, Merrill JP. Acute renal failure following cardiac operations. J Thorac Cardiovasc Surg. 1980;79:241-3.

9. Huen SC, Parikh CR. Predicting acute kidney injury after cardiac surgery: a systematic review. Ann Thorac Surg. 2012;93:337-47.

10. Lagny MG, Jouret F, Koch JN, Blaffart F, Donneau AF, Albert A, et al. Incidence and outcomes of acute kidney injury after cardiac surgery using either criteria of the RIFLE classification. BMC Nephrol. 2015;16:76.

11. O'Neal JB, Shaw AD, Billings FT IV. Acute kidney injury following cardiac surgery: current understanding and future directions. Crit Care. 2016;20:187. 